\title{
Investigation on the Development of Preschool Education Informationization of Ethnic Region in Gansu, China
}

\author{
Yanhua $\mathrm{He}^{1}$ \\ ${ }^{1}$ School of Modern Education Technology, Northwest University for Nationalities, PO box 730124 Lanzhou, P.R. \\ China \\ Correspondence: Yanhua He, School of Modern Education Technology, Northwest University for Nationalities, PO \\ box 730124 Lanzhou, P.R. China. E-mail: 136027328@qq.com
}

Received: June 29, 2015

Accepted: August 13, 2015

Online Published: August 17, 2015

doi:10.5430/ijhe.v4n3p161

URL: http://dx.doi.org/10.5430/ijhe.v4n3p161

\begin{abstract}
This paper investigates the informationization situation of preschool education taking Linxia City in Gansu province. The analysis was conducted by the mean of questionnaire survey and individual interview which was collected in July 2013 in seven ethnic counties in Hui autonomous prefecture of Linxia. As a typical ethnic region, Linxia can reflect the overall minority situation in preschool education informationzation in Gansu province, China. The purpose of this paper is to seek suitable early childhood education more practical and constructive solutions exploring the information road of preschool education and providing effective decision support for the development about the related preschool education in Gansu ethnic regions as a whole.
\end{abstract}

Keywords: Preschool education, Information technology, Teaching, Information literacy

\section{Introduction}

Preschool education is an important part of basic education, and it is the starting point of the whole national education, and it is the foundation stage of school education and lifelong education. Therefore, all levels of government and relevant departments attach importance to the development of preschool education. The report shows that China's early childhood education information work has got results. The Ministry of education officials and education experts called for the strengthening of China's early childhood education work, to effectively use the advanced technology, to build a solid foundation for the education. The supporting of relevant theory and practice and implement of quality education promote the reform of preschool education curriculum the development of preschool teachers' professional.

Preschool education informationization is an important part of the national informationization and education communication. It is the appropriate use of informationization technology in the preschool education to develop appropriate early learning digital educational resources, optimization of preschool teaching activities to cultivate informationization literacy in young children to promote children's learning and development process. Wang (2008), Nang (2009), Li (2010), Zhu (2011) etc carried on the deep discussion on the concept of pre-school education informatization and pointed out that the development of education informatization is a dynamic process, and widely used in the field of modern information technology in education process, it is the process of development and utilization of information technology education resources and optimize the education teaching process, eventually to promote the reform and development of education. Xiao (2011) argued that education informationization is the informatization of education industry, also contains information resources, information network, information technology application, information industry and information technology, information talents and six elements such as policies, regulations and standards. By investigating the pre-school education of Guizhou ethnic areas, Wang (2007) stated that preschool education informatization development cannot be completely to use the model of primary and secondary school education informatization, preschool education informationization is different from the primary and secondary school education informatization, it is more requirement from young children's physical and mental development. Guo (2011) proposed pre-school children living in the computer era, they must not only learn from the computer, but also need to learn the computer. Chen (2012) emphasizes "suitability" in pre-school education informationization, which is different from the distinctive characteristics of primary and secondary school education informatization. $\mathrm{Li}$ (2011) pointed out that despite the conditions of the kindergarten website home page has been established, but the role of the site was only focused on the kindergarten publicity, share the teaching 
information between teachers and the interaction between teachers and parents. In summary, with the promotion of the position of preschool education and deeper understanding of preschool education informatization, preschool education informatization research become the focal point, and made some progress. The preschool education informationization work time is short in China, there are still some problems that can not allow ignoring as: (1) on the macro regional development imbalance: (2) on the micro internal application uncoordinated: (3) the development path is not clear. Therefore, by questionnaire and interview, the paper analyzes various causes of preschool education informationization for the present situation and problem, seeking some practical and constructive method, exploring the development path of preschool educational information.

\section{Survey Design and Data}

Gansu is an agricultural province with ethnic regions and poor education in China. Hui autonomous prefecture of Linxia is located in the central and southern Gansu province which provide the place for the hui, han, dongxiang, bao'an, salar, tu, Tibetan and other 22 national more than 200 people of all ethnic groups. The survey is made to divide the kindergarten properties and quality grade (public, private and demonstration, non demonstration). Secondly, the random sample of 120 kindergarten principals and teachers were chosen as the research object. The 120 kindergartens are distributed in Guanghe, Kangle, Jishishang, Yongjin, Linxia, Hezheng and other cities, towns and villages. In order to reflect the actual situation, the researchers also take into account the open design of the questionnaire, mainly including the choice and the freedom to fill in the two categories

Using the method of questionnaire survey and interviews, the questionnaire survey includes equipment of school, awareness and attitude of modern teaching, teachers' information literacy and the modern means of teaching ability, acceptance of education technology training. The questionnaire is divided into principal and teacher questionnaires. Principal questionnaires designed 41 questions, teacher questionnaire design of 44 questions, covering many aspects of preschool educational information. The survey was distributed in 760 copies, 687 copies, 641 of which were valid questionnaires, the recovery rate was $90.39 \%$, and the effective rate was $93.30 \%$.

\section{Survey Results and Analysis}

\section{1 main conditions of the construction for information infrastructure}

\subsubsection{The kindergarten multimedia hardware equipment}

According to the survey, the kindergarten multimedia equipment configuration as shown in Figure 1, The kindergarten allocation rate reached more than $70 \%$ of the equipment: networked computer equipment, tape recorder, television, including recording machine configuration rate reached $92 \%$, voted in history education application is more dominant. Projector and projector, digital camera (photo) camera configuration is less than 50\%. Visible, kindergarten the configuration of equipment and traditional teaching tools, such as tape recorder based, modern teaching tools, such as projectors and projector over $50 \%$ of the kindergarten is not configured, even if, it is the traditional teaching tools have $30 \%$ of the kindergarten without any configuration. Kindergarten in infrastructure construction of Linxia City is still at a low level, it shows that people for the information technology teaching equipment is still relatively narrow understanding.

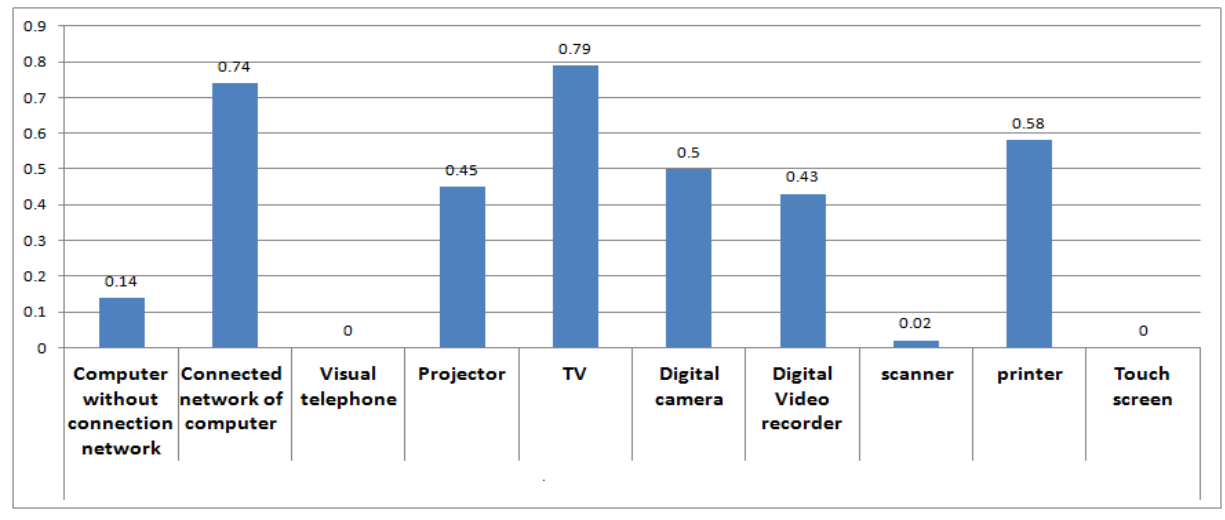

Figure 1. the usage of multimedia equipment 


\subsubsection{The information system of the kindergarten education}

Figure 2 shows that at present in Linxia area, $52 \%$ of the kindergarten configuration have multimedia classroom, $38 \%$ of the kindergarten configuration has broadcast system, only $24 \%$ of a kindergarten configured professional computer classrooms. However, in video conference rooms, lecture hall and other informational teaching environment are few numbers, visible, most kindergartens lack of the teaching about the information environment, the overall low level of teaching of information technology.

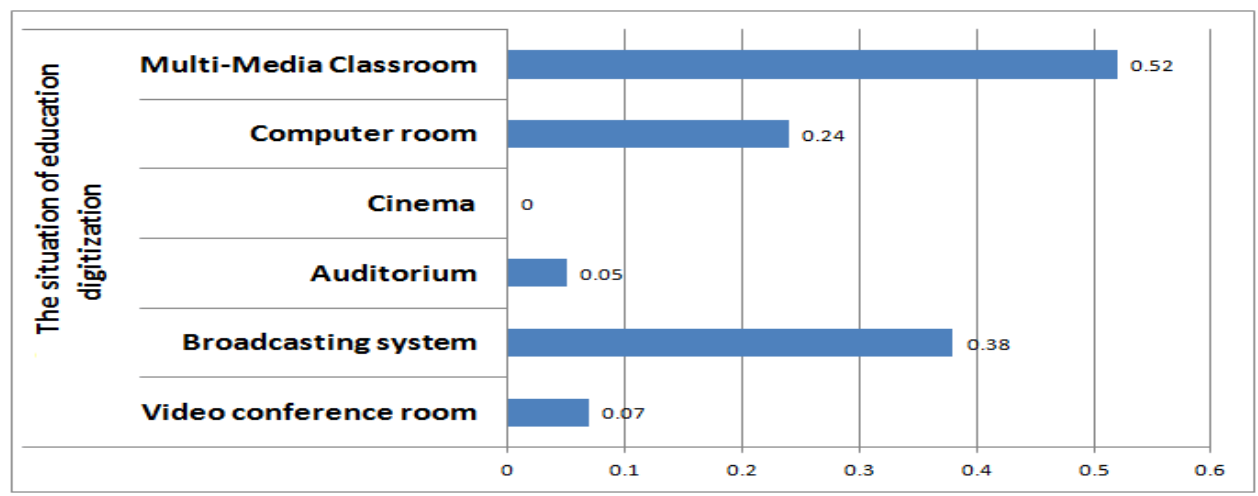

Figure 2. the education informationzation system

\subsubsection{The Kindergarten Website (WEB) Penetration Rate is 36\%}

From Figure 3 we can see that the role of the nursery site has three major aspects, namely kindergarten education, teachers to share teaching information, the interaction between teachers and parents. According to the survey, the communication between teachers and parents is only the change of information, such as the kindergarten curriculum, teaching and other information from the web page, it is not a real sense of interactive communication.

And in early childhood autonomous learning to zero, that the kindergarten and no consciousness at an early age to cultivate children's information ability and information literacy, only resource was also used to as a teaching tool and publicity, but also part of the kindergarten do not have a website.

3.1.4 The application of information technology in subject teaching.

From Figure 4, most of the teachers think that it is suitable for the use of information technology and the teaching about art is the most suitable for the use of information technology. And in the "health" education field is low, the teacher is also aware of the computer equipment will have a negative effect on children's vision and other health.

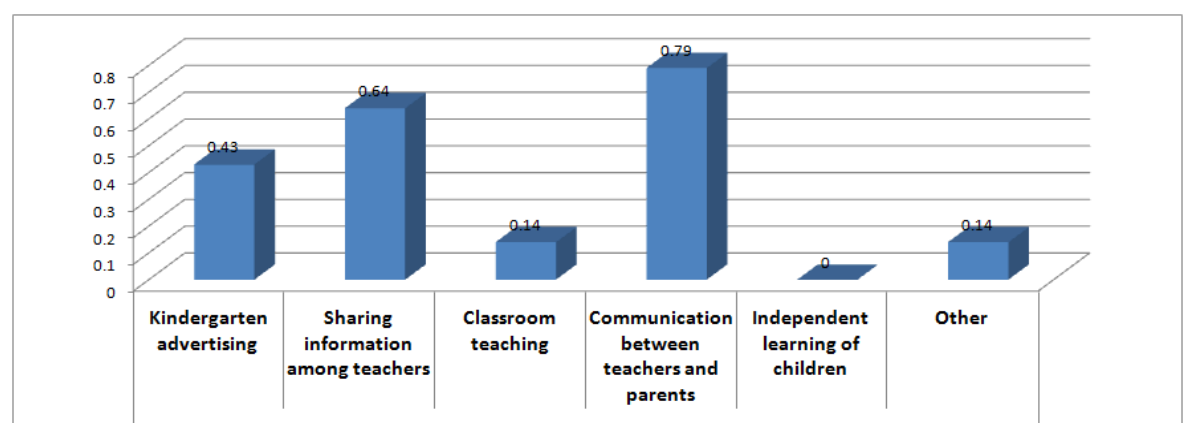

Figure 3. the degree of web site distribution 


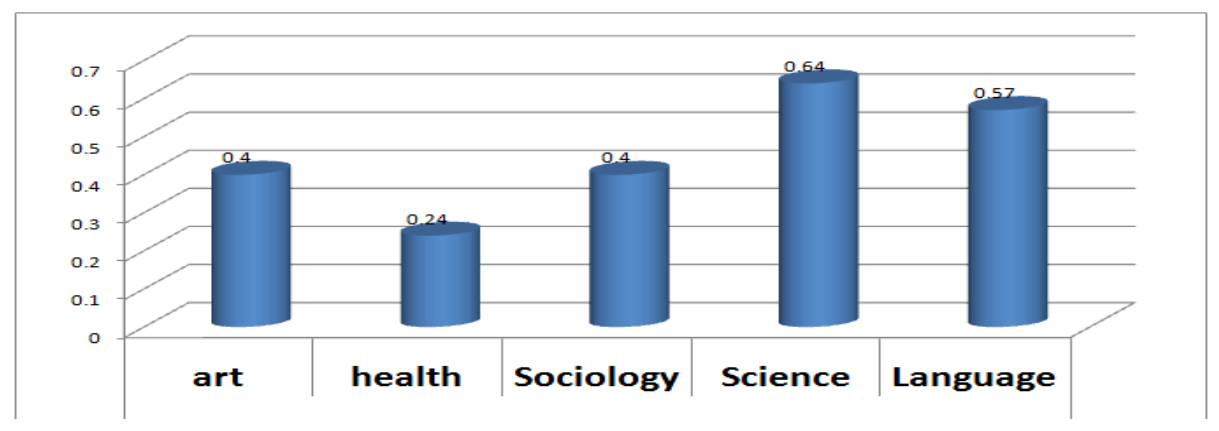

Figure 4. application of information technology in teaching

\subsection{The Basic Information Literacy of Kindergarten Teachers}

\subsubsection{The use of multimedia equipment teaching in the usual teaching of kindergarten}

As shown in the Figure 5, which is usually used in the multimedia teaching? In kindergarten teaching, the use of most of the information teaching method is teaching, which is also equipped with a rate of $92 \%$. Secondly, the use of multimedia courseware is $48 \%$, while the number of teachers with the rate of $52 \%$, indicating that there are $4 \%$ equipped with multimedia classrooms, kindergartens and not makes full use of these resources. TV teaching and projection teaching were $33 \%$ and $36 \%$ respectively. The rate of the network course and courseware is nearly $7 \%$.

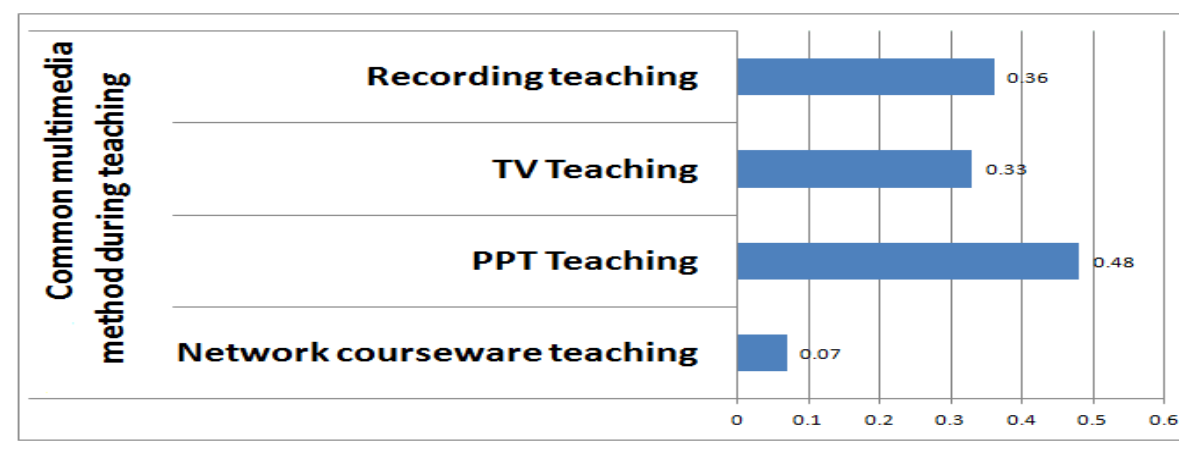

Figure 5. common multimedia method in teaching

The use of multimedia equipment in teaching. As shown in Figure 6, the use of multimedia equipment in Teaching.

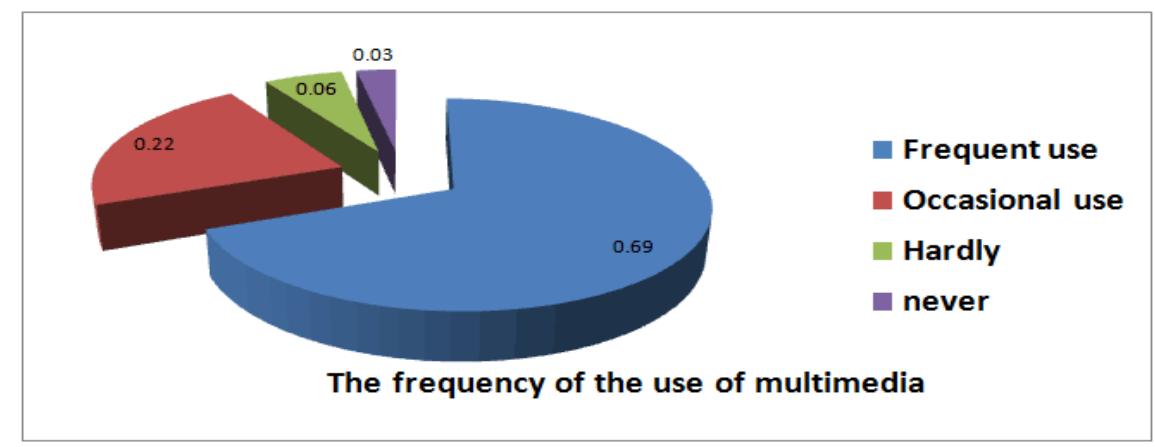

Figure 6. the frequency of the multimedia 


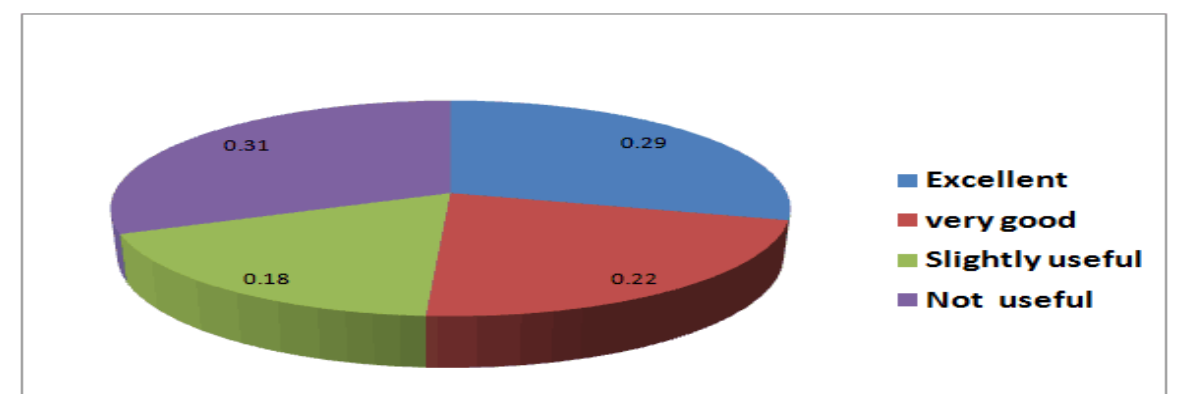

Figure 7. attitude of teachers for multimedia teaching

According to the survey, only $22 \%$ of the teachers occasionally use the multimedia equipment, while $69 \%$ of the teachers occasionally use, almost no and never used were $6 \%$ and $3 \%$. Thus, most of the teachers are occasionally used. First of all, it is an effective use of multimedia equipment and teaching resources. Secondly, it is the teacher's information ability and information literacy is low, it is difficult to realize the education information.

Teachers' attitude towards multimedia teaching can be seen in Figure 7. For the attitude of multimedia teaching, only $29 \%$ and $22 \%$ of the teachers think are very good, there are still $31 \%$ of the considered useless. This shows the teachers using the multimedia teaching, there is a lot of confusion and misunderstanding, and it is a resistance to achieve the information of the nursery.

3.2.2 The actual situation of teachers' information literacy and the ability to use modern means of teaching

Teachers will use multimedia: As shown in Figure 8, in preschool teachers of multimedia hardware control, like recorders, televisions, computers and other traditional teaching equipment have a better command of projector and projector only $42 \%$ would use. Printers, digital cameras and other equipment and a considerable part of the teachers will not use.

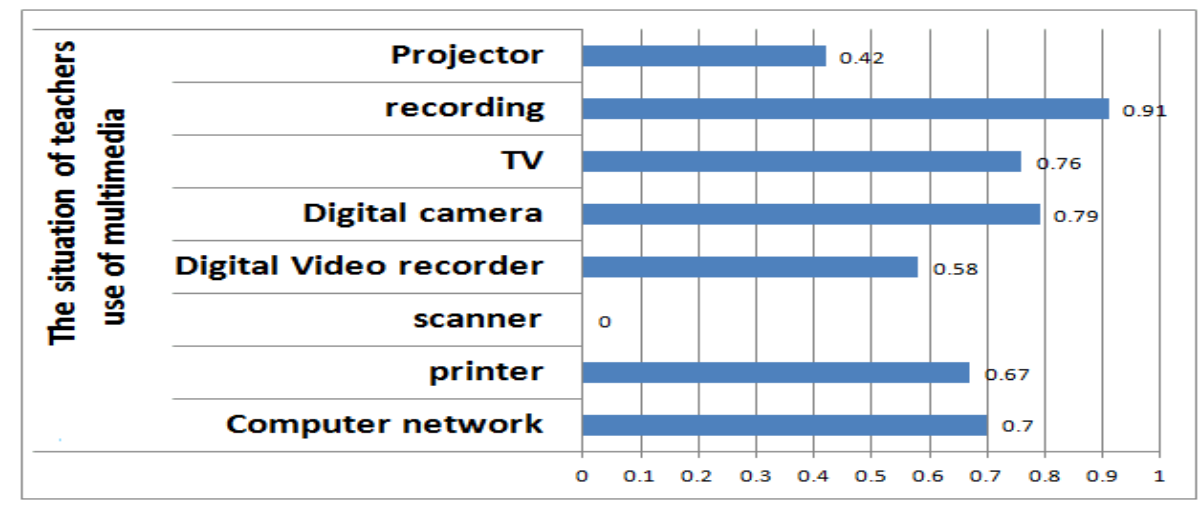

Figure 8. the situation of teachers using of multimedia

\subsubsection{Six skills analysis}

From Table 1, it can be seen that according to the teaching need to choose appropriate teaching methods and content organization, expression, transmission, processing, handling and information on a variety of teaching were analysis, identification, evaluation and appropriate use of these three types of information, the majority concentrated in general at this level, while the "very good" and "good" in only a small number of people.

According to the teaching needs of the production of relevant software, $29 \%$ are not good, only $14 \%$ of the more good, which shows that teachers are relatively lack of this ability. In the information resources from the rich to select the required information, to understand the knowledge of the discipline front, very good at and generally good at are $27 \%$. This shows that the ability of the teacher's information is still relatively poor. 


\section{3 preschool teachers to accept the information technology training}

3.3.1 The results show that support for teachers to participate in information technology training needs to be strengthened.

$64 \%$ of the kindergarten occasionally start the training of information technology teaching, and $9 \%$ of the kindergarten has never been with information relevant to the teaching of training, often carry out the training of kindergarten is less than the total number of $1 / 3$. And with the terms of quality, training is to meet the expected standards, whether or not to meet the needs of teachers, whether for regular and systematic training, it is the most important criterion in consideration of information technology teaching and training

\subsubsection{Teachers' demand for training.}

The teacher training content is the most needed for the use of multimedia teaching equipment and courseware production skills, teaching design training has a great demand. In a word, teachers in the training content of the various aspects which has a great demand.

\subsubsection{The effect of teachers on training}

According to the results of the survey, $52 \%$ of the teachers think that accept the training effect in general, preschool teacher education technology training has many problems, the training efficiency is not high. The private kindergarten received less training and training methods are monotonous. The trainees can not meet the demand.

\subsubsection{The existing problems of preschool education informationization}

At present, the main problems of information education in kindergarten, teachers' level is not high, there is no support, many people choose to say is not clear, the main problem is concentrated in the absence of conditions for support. This shows that the kindergarten teachers lack of information thinking about teaching, and lack of conditions for support.

\section{Conclusion and Implications}

\subsection{To Strengthen Modern Education Technology Training and Improve the Information Literacy}

Teachers' ability information technology application is the core component of the information society teachers' information literacy. The information literacy of teachers is related to the teaching of information technology, the integration of information technology and subject, and the process of the whole education informationization. Often carry out educational technology training, in order to improve the ability of the development of the multimedia application about the preschool teachers, as well as the teaching ability of the media.

The training of teachers is not only understanding and operation of courseware, multimedia equipment, must also understand the theory of modern education technology, only the combination of the correct theoretical guidance, in order to improve multimedia teaching ability and teaching ability of information technology.

\subsection{To Strengthen the Construction of Information Infrastructure}

To provide a teaching platform for the information infrastructure is to develop and improve the information literacy of kindergarten teachers is the foundation, but also the guarantee of the realization of education information.

Information infrastructure in kindergarten has become a bottleneck in the development about the information process of preschool education. The core problem of infrastructure construction is education investment. Our government should draw on the experience of developed countries in the long-term interests of the country and national development.

\subsection{To Build up the Material Library and to Develop the Professional Teaching Resource Library.}

In this investigation, another important reason for the difficulty of using multimedia teaching is that the professional teaching resources are scarce. To establish an information platform for teachers to provide a matching teaching material needs to be made according to the educational objectives and the content of education, and it should be in accordance with the learning characteristics for children. The organization of professional personnel to the use of courseware, pictures, text information, experience and other valuable resources for the collection, preservation and Integration for the daily teaching and exchange of teaching. According to the characteristics of physical and mental development of different age of stages and teaching needs, the classification and establishment of material library, through the campus local area network or campus website sharing. 
4.4 To Narrow the Gap and Promote Balanced Development.

Linxia City District has obvious gap, some kindergarten seems poor, not to mention the informatization construction. We must increase investment in information education in underdeveloped areas, raise funds in various ways, and actively encourage policies to reduce the gap. For some areas of the lack of software and hardware facilities and the curriculum reform of the curriculum is difficult to carry out the problem, Government departments must take positive policy to balance the education resources, The relevant departments should take effective measures to achieve the full development of kindergartens in time.

\section{Acknowledgements}

This work was supported by the Fundamental Research Funds for the Central Universities of Northwest University for Nationalities (Grant No.ZYZ2012039).

\section{References}

Chen-Heng Lin. (2012)Application of A Model for the Integration of Technology in Kindergarten: An Empirical Investigation in Taiwan. Early Childhood Education Journal, 40(1): 5-17. http://dx.doi.org/10.1007/s10643-011-0494-5

Cheng Jiangrong, Xie Yueguang. (2011). the evaluation index system of rural primary and middle school education informatization. Chinese audio-visual education, (2).

Guo Liping, Lai Jiaxin. (2011). thinking and prospect of Chinese preschool education informationization. Early childhood education, (36).

Nan Gounong. (2004). An introduction to education. Higher education press.

Liu Zhengfang. (2010). Child care survey and analysis of teachers 'information literacy. Modern education technology, (11).

Li Bingde. (2011). Methods of educational science. People's education press.

Li Hongyun, Jin Hongyan. (2008). Multimedia computer teaching, to promote the development of children's comprehensive quality. Audio visual research, (4).

Liu Zhenghe. (2007). Preschool information investigation and analysis of status quo and countermeasures in Zhejiang Province. China audio visual.

Wang Yunwu, Chen Lin. (2008). Comparative study on the informatization of Chinese and foreign education. Beijing: Publishing House of electronics industry, 35.

Wang Yongjun. (2007). Early childhood teachers ' information literacy and its cultivation of young--to Anhui provincial authorities kindergarten as a case study. East China Normal University.

Yuan Guiren. (2003). New encyclopedia of China (early childhood volume). Encyclopedia of China Publishing House. 